\title{
SEISMIC PERFORMANCE OF FRICTION PENDULUM BEARING BY CONSIDERING STOREY DRIFT AND LATERAL DISPLACEMENT
}

\author{
Vindhya Bhagavan ${ }^{1}$, G.V Sowjanya ${ }^{2}$, Chethan Kumar $B^{3}$, Sandeep Kumar D.S ${ }^{4}$ \\ ${ }^{1}$ Post graduate Student, Dept of civil engineering, SSIT, Tumkur, Karnataka, India \\ ${ }^{2}$ Asst professor, Dept of civil engineering, SSIT, Tumkur, Karnataka, India \\ ${ }^{3}$ Asst professor, Dept of civil engineering, VVIT, Bangalore, Karnataka, India \\ ${ }^{4}$ Asst professor, Dept of civil engineering, PESCE, Mandya, Karnataka, India
}

\begin{abstract}
Base Isolation technique is used to decouple the base from its superstructure during the ground motions caused by earthquake. The present study is done on a G+4 storey building, considering three models where the first model indicates the bare frame structure, second model indicates the with infill structure which is modelled as equivalent diagonal strut and the third model indicates the base isolated structure using friction pendulum bearing. The main objective is to study the dynamic response of with infill and without infill structure and carrying design of FPS for the maximum response of structure such as lateral displacement and storey drift. The dynamic analysis of with infill and without infill structure indicated that the structure is stiffer with infill effect and structural response also get reduces. The base isolated structure reduces the inter storey drift and lateral load effects on the structure.
\end{abstract}

Keywords: Friction Pendulum Bearing; ETABS 9.7.3; Infilled Frame; Equivalent Diagonal Strut.

- ***

\section{INTRODUCTION}

The concept of base isolation system had been suggested in last few decades and the available technologies and the knowledge of base isolation system are getting mature and well established. Seismic isolation systems are more effective when applied to high stiffness, low-rise buildings, owing to their abilities to alter the characteristic of the building from rigid to flexible. An increasing number of structures to be isolated reflect the fact that base isolation system is gradually becoming accepted as a proven technology in earthquake hazard mitigation. Base isolation is an anti-seismic design strategy that can reduce the effect of earthquake ground motion by decoupling the superstructure from the foundation. The structure can be decoupled from the horizontal components of the ground motion by interposing structural elements with low horizontal stiffness between the foundation and superstructure [1]. To minimize the transmission of potentially damaging earthquake ground motions into a structure is achieved by the introduction of flexibility at the base of the structure in the horizontal direction while at the same time introducing damping elements to restrict the amplitude or extent of the motion caused by the earthquake somewhat akin to shock absorbers. In recent years this relatively new technology has emerged as a practical and economic alternative to conventional seismic strengthening. This concept has received increasing academic and professional attention and is being applied to a wide range of civil engineering structures [2].

\section{TYPES OF ISOLATOR}

Many types of isolation system have been proposed and have been developed to varying stages, such as elastomeric bearings, Lead plug bearings, Friction pendulum bearings .In the present study we considered the friction pendulum bearings . The cross section of bearing is as shown in Fig-1.

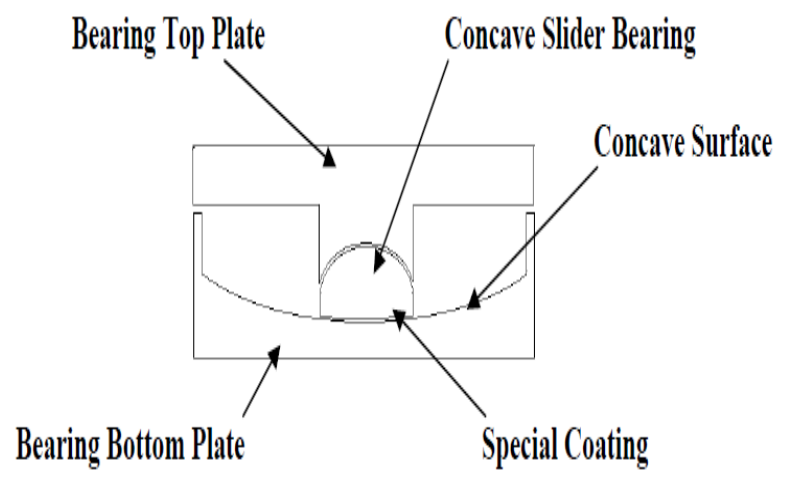

Fig-1: Cross-section of a friction pendulum bearing

\subsection{Friction Pendulum Bearing}

The friction pendulum system (FPS) is a widely used bearing based on the principle of sliding system and with a pendulum type isolator to provide a damping function using friction. The FPS isolator has an articulated slider moving on a spherical friction surface. The surface of the articulated slider in contact with the spherical friction surface is all coated with a self-lubricating composite material. The other side of the slider is attached to the stainless steel concave, spherical surface and also covered with low-friction composite material. When the slider moves over the 
spherical surface, the supported mass will be lifted and the movement will provide the restoring force to the system. Under extreme loads such as earthquakes, the slider moves along the concave surface, causing the supported structure to move in small arcs like a pendulum. The isolators reduce transmission of the earthquake forces to the structure by deflection (the pendulum motion) and by friction (damping) on the sliders. The radius of the curvature of the concave surface will dominate the effective stiffness and the system period.

\section{INFLUENCE OF MASONRY INFILL WALLS}

Infills interfere with the lateral deformations of the $\mathrm{RC}$ frame, separation of frame and infill takes place along one diagonal and a compression strut forms along the other. Thus, infills add lateral stiffness to the building. The structural load transfer mechanism is changed from frame action to predominant truss action the frame columns now experience increased axial forces but with reduced bending moments and shear forces. When infills are non-uniformly placed in plan or in elevation of the building, a hybrid structural load transfer mechanism with both frame action, and truss action may develop. In such structures, there is a large concentration of ductility demand in a few members of the structure. For instance, the soft-storey effect (when a storey has no or relatively lesser infills than the adjacent storey), the short-column effect (when infills are raised only up to a partial height of the columns), and plan-torsion effect (when infills are unsymmetrical located in plan), cause excessive ductility demands on frame columns and significantly alter the collapse mechanism. Another serious concern with such buildings is the out of plane collapse of the infills which can be life threatening. Even when the infills are structurally separated from the RC frame, the separation may not be adequate to prevent the frame from coming in contact with the infills after some lateral displacement; the compression struts may be formed and the stiffness of the building may increase.

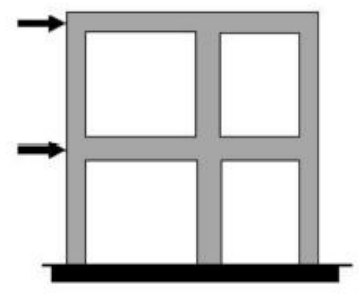

(a)

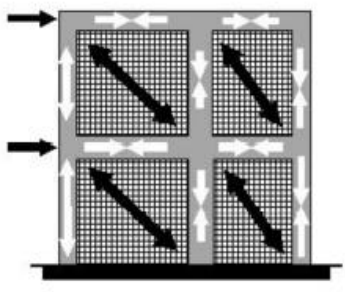

(b)
Fig-2: Change in the Lateral Load Transfer Mechanism owing to Inclusion of Masonry Infill Walls.(a) Frame Action in Bare Frame.(b) Predominant Truss Action in Infilled Frame

\section{EQUIVALENT DIAGONAL STRUT}

Stafford Smith (1966) developed the formulations for $\alpha \mathrm{h}$ and $\alpha \mathrm{L}$ on the basis of beam on an elastic foundation. The following equations are proposed to determine $\alpha$ h and $\alpha \mathrm{L}$, which depend on the relative stiffness of the frame and infill, and on the geometry of the panel.

$$
\begin{array}{ll}
\mathrm{W}={ }_{2} \sqrt{\propto_{h}^{2}+\propto_{L}^{2}} & \text { Equation-1 } \\
\propto_{\mathrm{h}}=\frac{\pi}{2} \sqrt[4]{\frac{4 E_{f} I_{c} h}{E_{m} t \sin 2 \theta}} & \text { Equation-2 } \\
\propto_{\mathrm{L}}=\pi \sqrt[4]{\frac{4 E_{f} I_{b} L}{E_{m} t \sin 2 \theta}} & \text { Equation-3 }
\end{array}
$$

Where $E_{m}$ is Elastic modulus of masonry wall, $E_{f}$ is the Elastic modulus of frame material, $t$ is the thickness of infill $h$ is the height of the infill L length of the infill, $I_{c}$ and $I_{b}$ are moment of inertia of column and beam. The values of $\mathrm{E}_{\mathrm{m}}$ is $14800 \mathrm{~N} / \mathrm{mm}^{2}$ and $\mathrm{E}_{\mathrm{f}}$ is given by $5000 \sqrt{f_{c k}}$

\section{OBJECTIVES}

The objectives of the study are:

- To study the dynamic effect of Infill masonry structure to bare frame structure.

- To design the base isolator.

- $\quad$ To carry comparative study between base isolated structure \& normal building.

- To study the response such as model time period.

- To study the response of structure such as lateral displacement, story drift.

\section{DESIGN FLOW CHART FOR FPS BEARINGS}

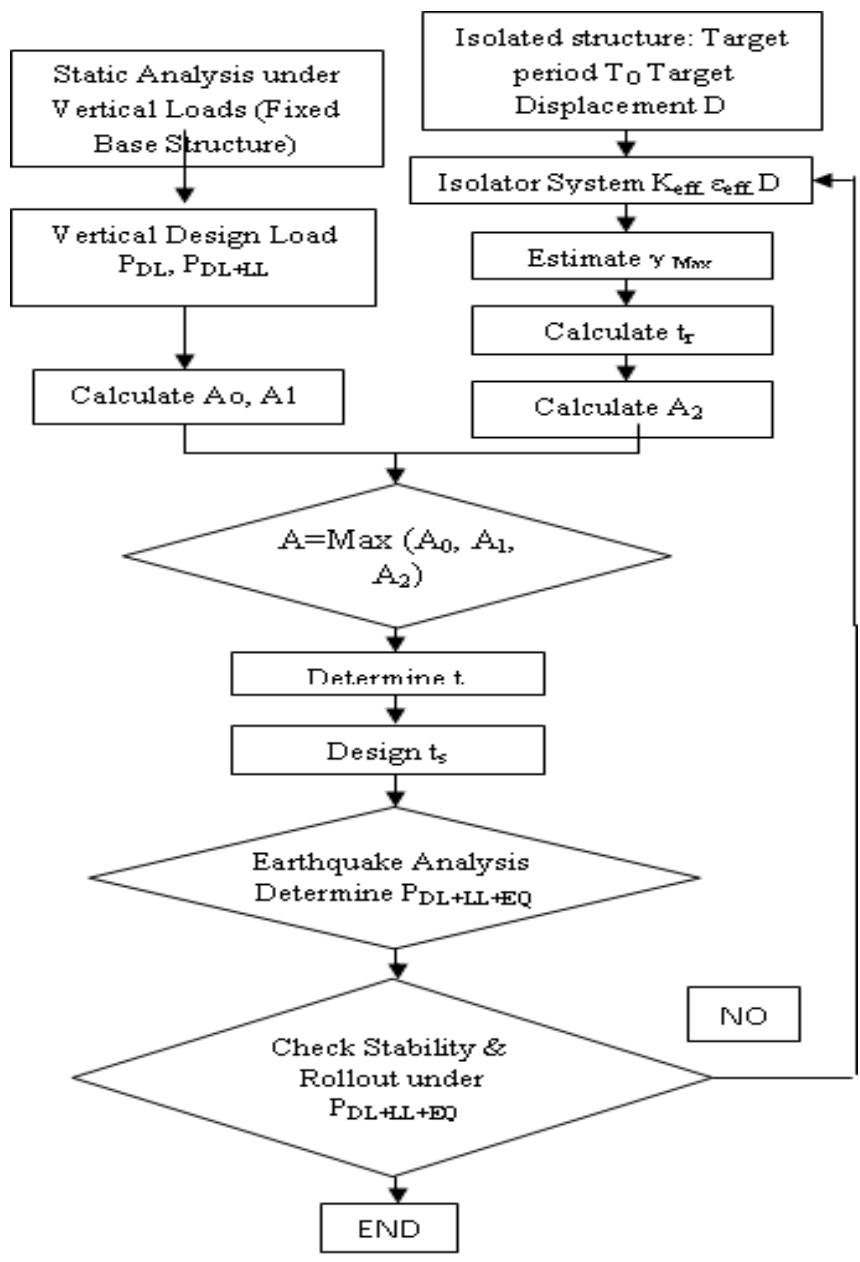




\section{MODELING AND ANALYSIS}

The three different building models are analyzed in Etabs as shown in Fig-3, 4, 5.

\subsection{Model 1}

The properties of the considered building configurations in the present study are summarized below:

- $\quad$ Height of each floor: $3 \mathrm{~m}$

- Plan dimensions of each storey block: 6X5m

- $\quad$ Floor thickness: $0.15 \mathrm{~m}$

- Wall thickness: $0.2 \mathrm{~m}$

- $\quad$ Parapet wall thickness: 0.15

- Density of concrete: $25 \mathrm{KN} / \mathrm{m}^{3}$

- Live load: $3 \mathrm{KN} / \mathrm{m}^{2}$

- Floor finish: $1 \mathrm{KN} / \mathrm{m}^{2}$

- Poisson ratio of concrete: 0.15

- Poisson ratio of masonry: 0.16

- Damping: 0.05

- Size of column: 200X450mm

- $\quad$ Size of beams: 200X450mm

The structural material is assumed to be isotropic and homogenous. Joint between the building elements has been modelled by using semi-rigid diaphragm as constraints.

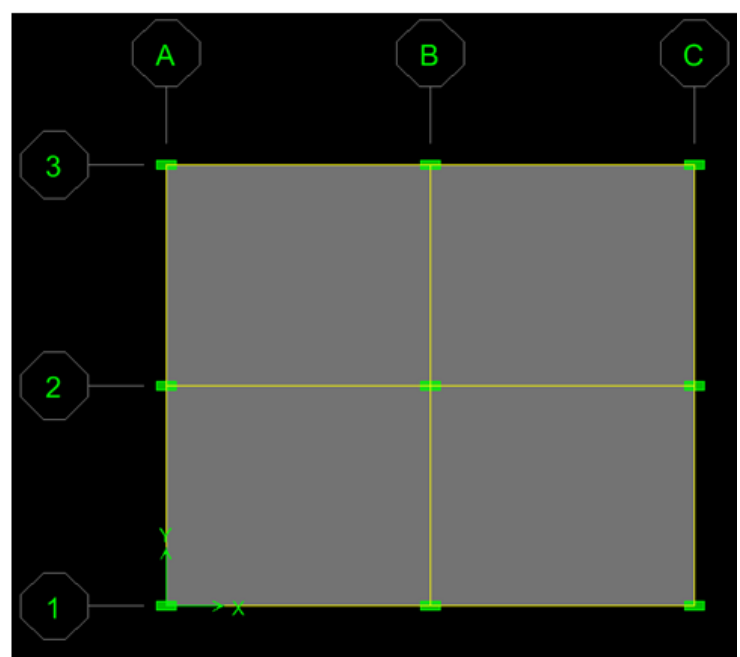

Fig-3: Plan of Model 1

\subsection{Model 2}

Infill has been modelled as equivalent diagonal strut as discussed in previous section, the effective width comes almost $0.77 \mathrm{~m}$ along longitudinal section( $\mathrm{X}-$ axis $) \& 0.64 \mathrm{~m}$ along transverse direction (Y-axis), and modulus of elasticity of masonry is considered as $14800 \mathrm{~N} / \mathrm{mm}^{2}$, Poisson ratio of conventional brick is 0.16 .

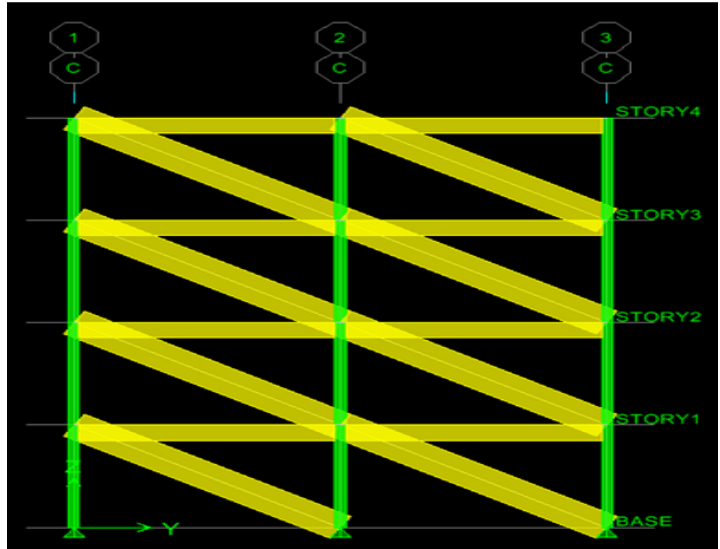

Fig-4: Elevation of Model 2 Showing Diagonal Strut along different story level

\subsection{Model 3}

Friction pendulum bearings have been modelled as ISOLATOR 2 using link element in Etabs.

The dialog box for the properties of friction pendulum Bearing is as shown in Fig 6 ,

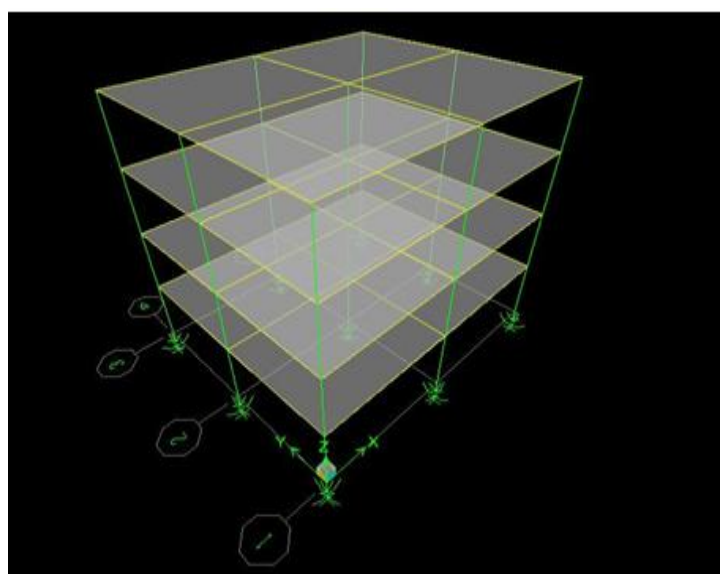

Fig-5: 3D Model of G+4 Building Along With Friction Pendulum Bearings at the end of Column

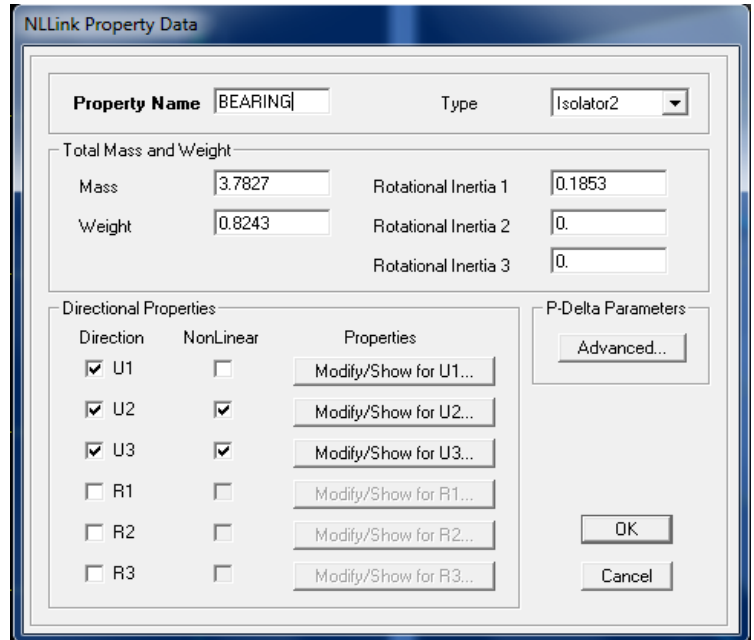

Fig-6: Link property dialog box to model friction Pendulum bearings 


\section{RESULTS}

8.1 Dynamic Analysis Effect of With Infill and Without Infill

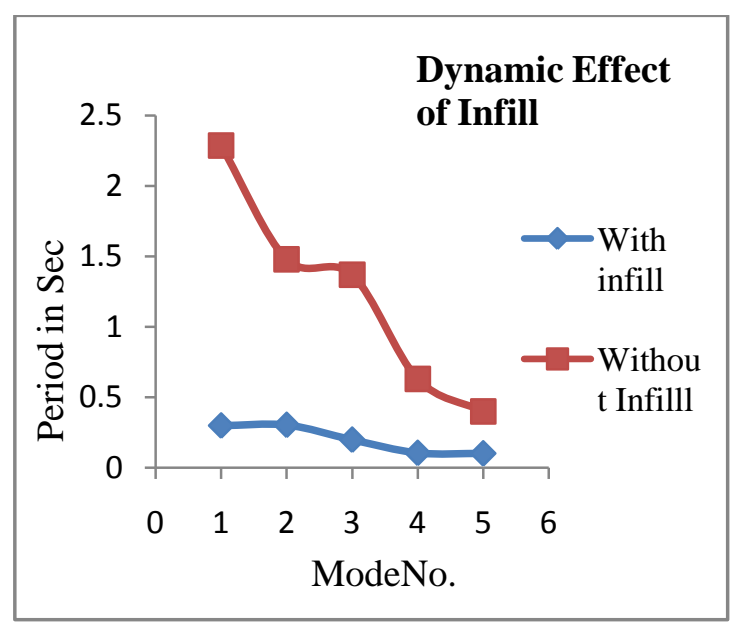

Fig-7: Plots between Time Period V/S Modes

Fig 7 clearly shows that increase in the time period without infill to with infill by this we can say that structure is stiffer with infill effect and structural response also get reduces \& this effect can be effectively utilized in design of structural elements.

\subsection{Maximum Lateral Storey Displacement}

\section{Comparison between Zone to Zone Displacements}

in Bare Frame Structure, with Infill Structure and

\section{Base Isolated Structure}

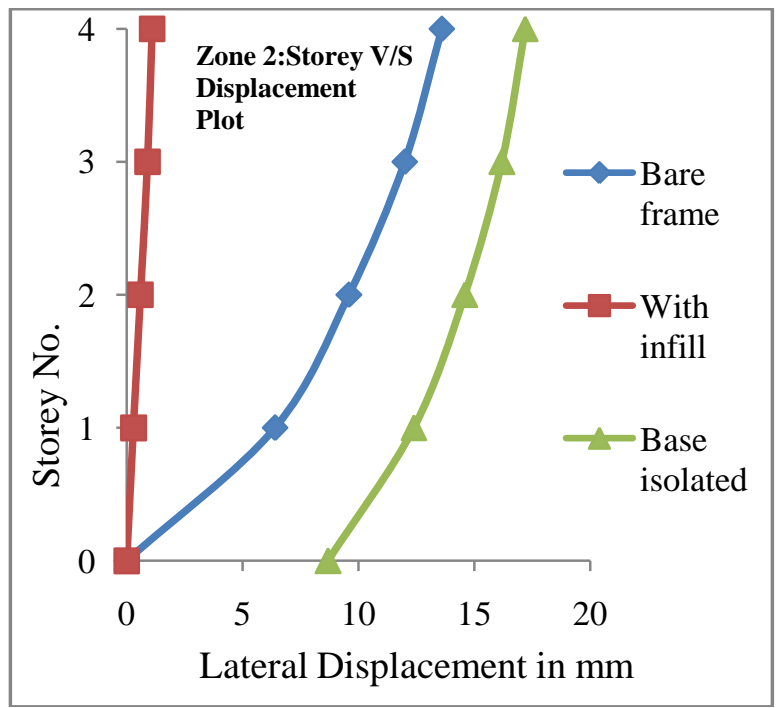

Fig-8: Plots between Storey V/S Max. Lateral Storey Displacements for Zone 2

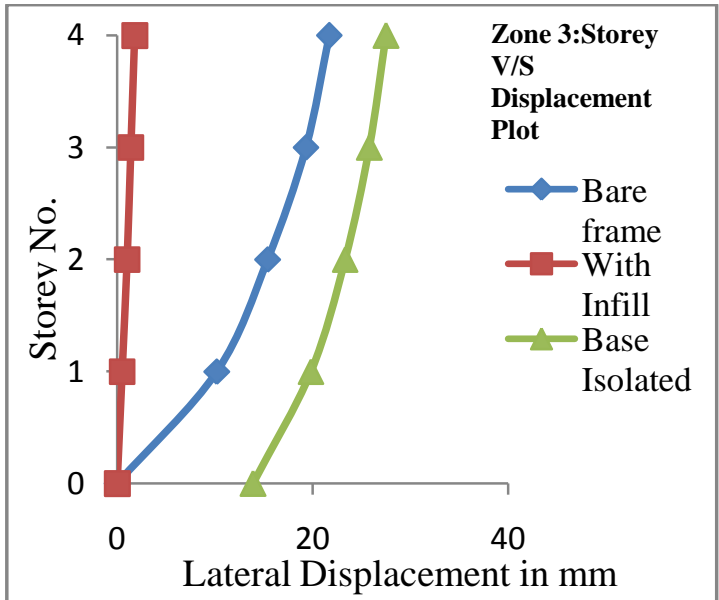

Fig-9: Plots between Storey V/S Max. Lateral Storey Displacements for Zone

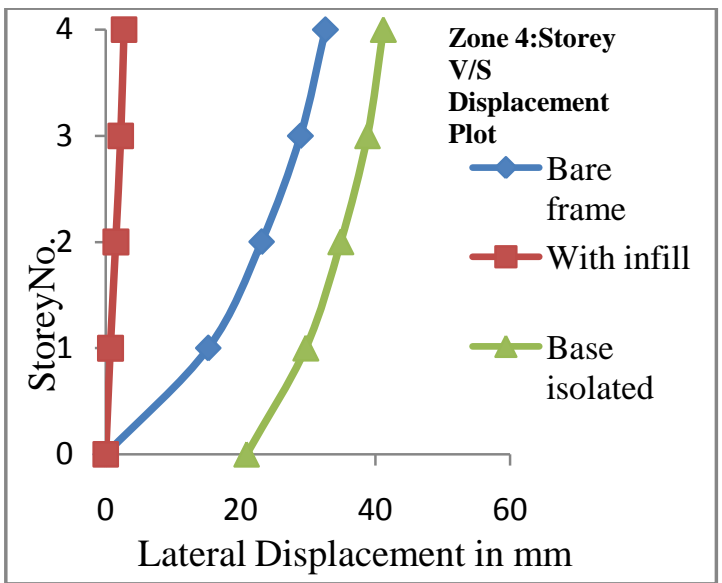

Fig-10: Plots between Storey V/S Max. Lateral Storey Displacements for Zone 4

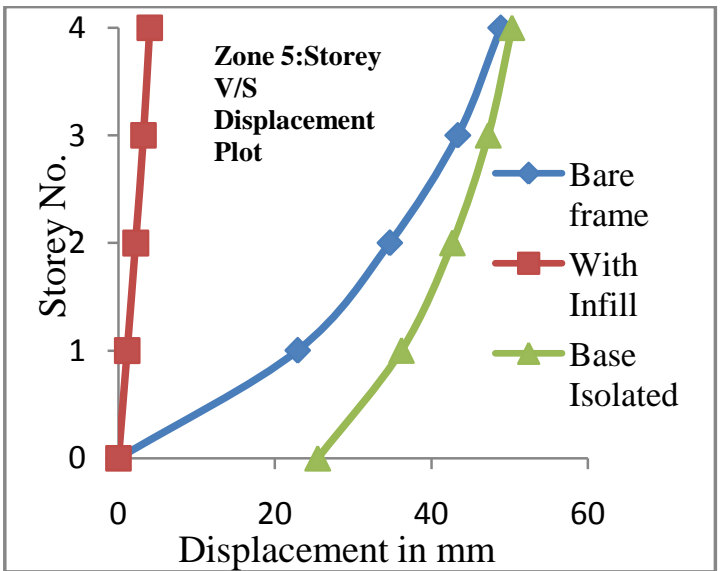

Fig-11: Plots between Storey V/S Max. Lateral Storey Displacements for Zone 5

The figures 8, 9, 10, 11 shows the graph draw between storey versus maximum storey displacement

The fixed base infill structure is have more stiffness and it is having minor displacement at the top, the displacement is gradually decreases storey to storey and finally at the base the displacement equal to zero. 
Similarly the fixed base structure without infill is having zero displacement at the base; the displacement is gradually increased to storey to storey. The top storey displacement is more than the fixed infill structure but it is lesser than the isolated structure.

The base isolated structure is having displacement at the base. It is increased storey to storey. At roof level it has maximum displacement compare to infill and without infill structure.

\subsection{Storey Drift}

Comparison between Zone to Zone Storey Drift in

Bare Frame Structure, with Infill Structure and

\section{Base Isolated Structure}

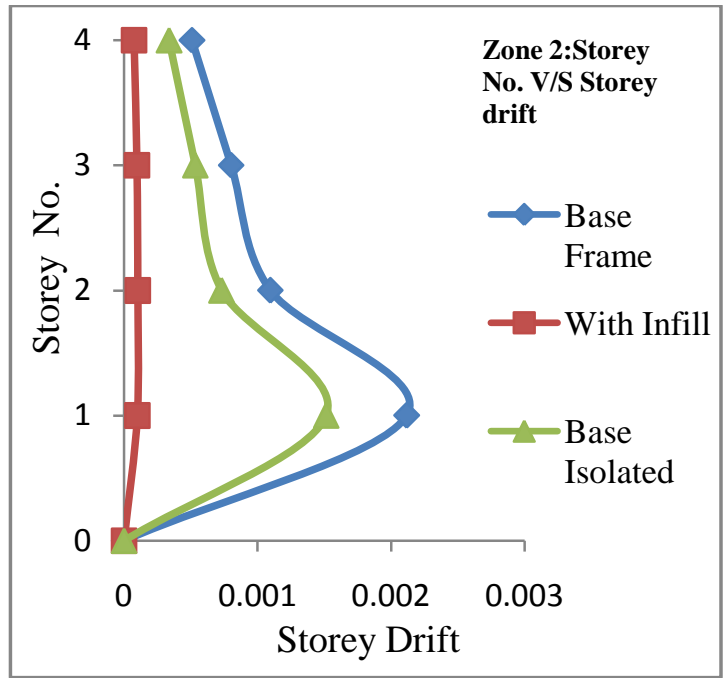

Fig-12: Plots between Storey No. V/S Storey Drift for Zone 2

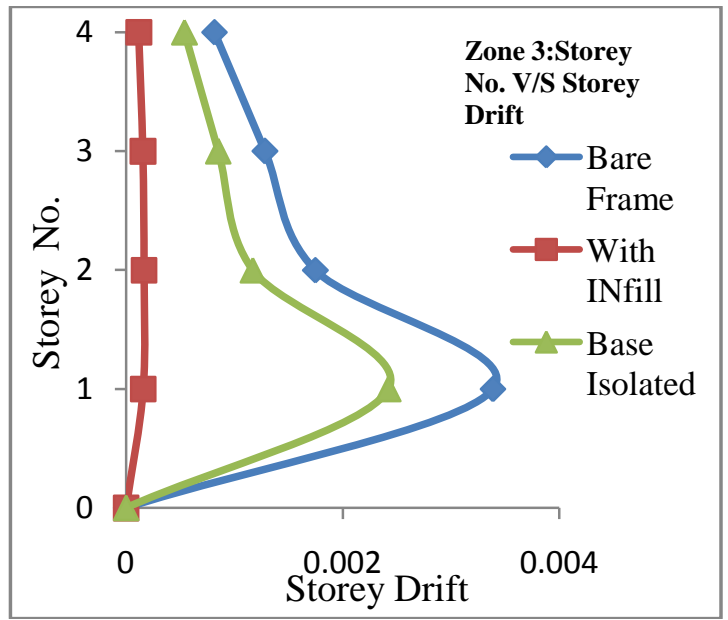

Fig-13: Plots between Storey No. V/S Storey Drift for Zone 3

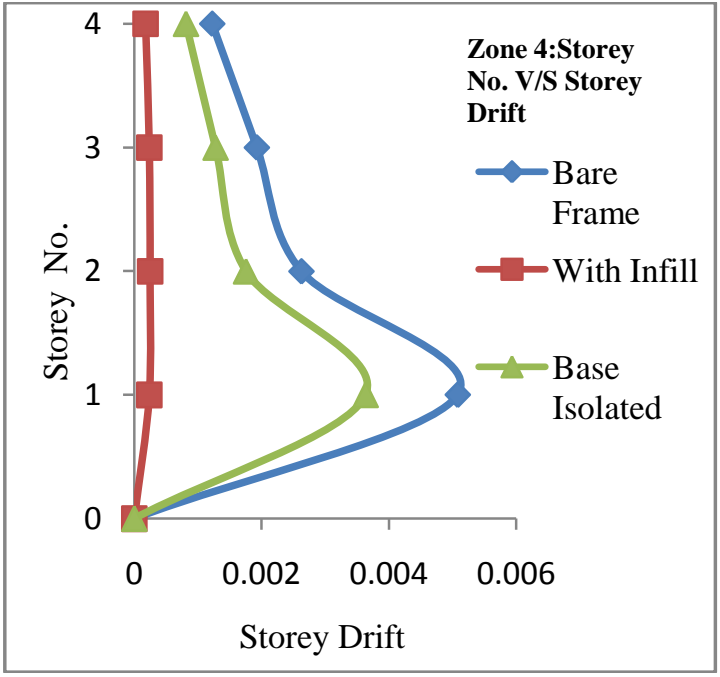

Fig-14: Plots between Storey No. V/S Storey Drift for Zone 4

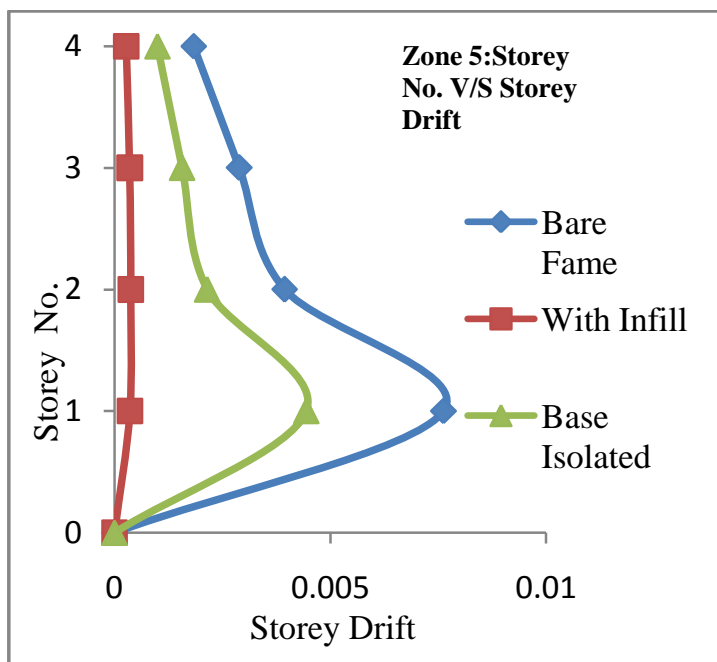

Fig-15: Plots between Storey No. V/S Storey Drift for Zone 5

The figures 12, 13, 14 and 15 shows the graph plotted between storey verses drift. In that the drifts have minor changes from base to top storey in the base isolated structure. The storey drift in with infill rapidly decreases from base to first storey. Then it decreases gradually for further storey height. Without infill structure have more storey drift compared to base isolated structure and with infill structure. This shows that by using isolated system we can reduce the storey drift.

The storey drift is the displacement of one level relative to the other level above or below. According to IS 1893-2002 finally permissible value of storey drift is $0.004 \mathrm{~h}$, where ' $h$ ' is storey height in $\mathrm{mm}$. Analysis shows storey drift of all structure are within permissible limit.

The storey drift in bare frame is increased to $95.32 \%$, $95.33 \%, 95.33 \%$ and $95.34 \%$ with zone 2 , zone 3 , zone 4 and zone 5 respectively with infill structure and decreased to $28.47 \%, 28.5 \%$ and $28.48 \%$ with zone 2 , zone 3 and zone 4 respectively in base isolated structure, but in zone 5 the storey drift decreased to $41.75 \%$ in the base isolated structure. 


\section{CONCLUSION}

The Effect of adding infill as diagonal strut increases the stiffness of the structure. Dynamic analysis of bare frame and infill frame reveals that infill counteract with the lateral forces due to earthquake and reduces building model time period. Simple steps for design of FPS type bearing have been represented in flowchart. Comparison of the dynamic response analysis between infill and without infill structure showed that the proposed model make design more economical. Increase in flexibility of system due to isolation increase of total displacement compare to infilled frame and bare frame structure. Implementation of the isolation system results into reduction of the inter storey drifts to negligibility level so it can be said that they practically don't exist. This reduction enables the structure to behave as almost ideally stiff. Storey drift values are within the permissible limit as specified in IS 1893-2002 i.e. 0.004 times of height of storey and inclusion of strut reduces storey drift value along with base isolation. Base Isolation Scheme was selected as best meeting the retrofit objectives and providing the most favourable performance.

\section{REFERENCES}

[1]. Tai-Chieh Wu, "Design of base isolation system for buildings", June 2001.

[2]. A.B.M. Saiful Islam, Mohammed Jameel and Mohd Zamin Jumaat, "Seismic isolation in buildings to be a practical reality: Behaviour of structure and installation technique", Journal of Engineering and Technology Research Vol. 3(4), April 2011, Page No. 99-117.

[3]. Nikolay Kravchuk, Ryan Colquhoun, and Ali Porbaha, "Development of a friction pendulum bearing base isolation system for earthquake engineering education", American Society for Engineering Education Pacific Southwest Annual Conference, 2008.

[4]. Anand S. Arya, "Concepts and techniques for seismic base- isolation of structures", Earthquake Engineering, 10th WCEE, 1994.

[5]. Christian Bucher, "Optimal friction pendulum systems for seismic isolation", the 8th International Conference on Structural Dynamics, 2011.

[6]. Fabio Mazza and Alfonso Volcano, "Base-isolation techniques for the seismic protection of rc framed structures subjected to near-fault ground motions", 13th WCEE, 2004, Paper No. 2935.

[7]. Luigi Petti, Fabrizio Polichetti, Alessio Lodato, Bruno Palazzo, "Modelling and Analysis of Base Isolated Structures with Friction Pendulum System Considering near Fault Events", Open Journal of Civil Engineering, , Vol 3, 2013, Page No. 86-93.

[8]. Vasant A. Matsagar, R.S. Jangid, "Influence of isolator characteristics on the response of base-isolated structures", IJG, 2010. Page No. 1521-1529. 